\title{
Desempenho e qualidade da carne de frangos de corte alimentados com diferentes níveis de sorgo em substituição ao milho
}

\author{
[Effects on performance and meat quality of replacing corn with sorghum in a broiler diet] \\ R.G. Garcia ${ }^{1}$, A.A. Mendes ${ }^{2}$, C. Costa ${ }^{2}$, I.C.L.A. Paz ${ }^{1}$, S.E. Takahashi ${ }^{1}$, \\ K.P. Pelícia ${ }^{1}$, C.M. Komiyama ${ }^{1}$, R.R. Quinteiro ${ }^{1}$ \\ ${ }^{1}$ Aluno de Pós-Graduação - FMVZ - UNESP - Botucatu, SP \\ ${ }^{2}$ Faculdade de Medicina Veterinária e Zootecnia - UNESP \\ Fazenda Experimental Lageado, s/n \\ 18618-000 - Botucatu, SP
}

\begin{abstract}
RESUMO
Avaliaram-se o desempenho e a qualidade da carne de frangos de corte alimentados com diferentes níveis de sorgo, do cultivar SAARA, com $0,49 \mathrm{~g} / \mathrm{kg}$ de tanino, em substituição ao milho. Os 2600 pintos sexados de um dia de idade, da linhagem Ross 308, foram distribuídos em delineamento inteiramente ao acaso, com esquema fatorial $5 \times 2$ (cinco níveis de sorgo - 0, 25, 50, 75 e $100 \%$ e dois sexos), e quatro repetições de 65 aves por unidade experimental. Não houve efeito $(\mathrm{P}>0,05)$ da substituição do milho pelo sorgo sobre as características de desempenho, de rendimentos de carcaça, carne de peito e pernas, de composição química e sensoriais. $\mathrm{O}$ pH observado nas carnes de peito e pernas foi maior para os machos $(\mathrm{P}<0,05)$, e houve diminuição do $\mathrm{pH}$ à medida que se aumentaram os níveis de substituição. Os machos apresentaram os maiores valores nas medidas de comprimento, largura e espessura do filé. Na carne do peito dos machos, ocorreu maior perda de peso por cozimento e força de cisalhamento $(\mathrm{P}<0,05)$. Observou-se diminuição $(\mathrm{P}<0,05)$ dos valores de a (vermelho) e b (amarelo) e aumento de $\mathbf{L}$ (luminosidade) à medida que aumentaram os níveis de substituição.
\end{abstract}

Palavras-chave: frango de corte, qualidade da carne, sorgo, tanino

\begin{abstract}
The effects of diets with graded levels of SAARA sorghum, a variety containing $0.49 \mathrm{~g} / \mathrm{kg}$ of tannin, on broiler performance and meat quality were evaluated. One-day-old, sexed Ross 308 chicks $(n=2600)$ were randomly assigned within sex to one of five levels of sorghum (replacement of 0, 25, 50, 75 and $100 \%$ of corn in the diet). There were 65 birds per experimental unit in 4 replicates of the 5 sorghum level $\times 2$ sex factorial design. Level of corn replacement by sorghum did not affect performance characteristics, carcass characteristics, main cut yield, muscle tissue chemical composition or sensory characteristics of the meat $(P>0.05)$. Muscle tissue from males had higher $p H$ values than that from females, and muscle $\mathrm{pH}$ decreased as sorghum replaced corn in the diet $(P<0.05)$. Loin length, width and thickness were larger for males. Breast meat from males had higher cooking loss and required greater shear force than breast meat from females $(P<0.05)$. With increasing level of sorghum in the diet, the $\boldsymbol{L}$ value (level of light) of breast and leg muscle increased, whereas $\boldsymbol{a}$ value (redness) and $\boldsymbol{b}$ value (yellowness) decreased $(P<0.05)$. In summary, replacing corn in the diet with increasing levels of sorghum did not affect live performance, carcass or main cut yields or meat quality, but muscle pH and color were affected.
\end{abstract}

Keywords: poultry, meat quality, sorghum, tannin

Pesquisa financiada pela Fundação de Amparo à Pesquisa do Estado de São Paulo Recebido para publicação em 24 de março de 2004

Recebido para publicação, após modificações, em 29 de setembro de 2004

*Autor para correspondência (corresponding author)

E-mail: garofallo@fca.unesp.br 


\section{INTRODUÇÃO}

O sorgo é um importante cereal, estando em quinto lugar no ranking de produção mundial, atrás apenas do trigo, do milho, do arroz e da cevada. É utilizado em todas as partes do mundo na alimentação humana e animal (Gualtieri e Rapaccini, 1990).

Uma das características do sorgo é ser mais resistente à seca que o milho, sendo esse um fator importante, pois a cultura pode ser implantada em regiões com baixa pluviosidade (Gualtieri e Rapaccini, 1990). Em geral, as variedades de sorgo apresentam maior conteúdo de proteína bruta que o milho (8,8 a 15\%), embora ela seja menos digestível. Seu valor em energia metabolizável, apenas $5 \%$ menor do que o encontrado em grãos de milho (Nutrient... 1994), contém um perfil uniforme de aminoácidos essenciais, apesar de ser deficiente em lisina, metionina e treonina.

Vários estudos relataram redução significativa no consumo de ração por frangos alimentados com dietas contendo sorgo (Ibrahim et al., 1991), e esse efeito tem sido atribuído ao sabor adstringente do tanino (Trevino et al., 1992). Entretanto, como as aves não apresentam paladar desenvolvido, parece improvável que o sabor seja a causa da diminuição no consumo de ração. Musharaf e Latshaw (1991) não encontraram redução significativa no consumo de ração para frangos de corte quando substituíram o milho da dieta por até $62 \%$ de sorgo.

Muitos trabalhos avaliaram o efeito da substituição total ou parcial do milho pelo sorgo em dietas de frangos de corte sobre os índices produtivos, porém pouco se sabe sobre sua relação com a qualidade da carne.

Segundo Rostagno (1977), os frangos de corte apresentam menor eficiência na utilização da energia metabolizável quando ingerem dietas formuladas com níveis de sorgo acima de $50 \%$. Assim, dietas com níveis de sorgo acima desse valor resultam na produção de carcaças com menor teor de gordura.

De acordo com Bressan (1998), os fatores mais preocupantes, ao substituir o milho pelo sorgo, são a variação na cor da carne crua e a variação na maciez após o cozimento. A pigmentação da carcaça de frangos de corte depende de fatores genéticos, sexo, idade, linhagem, método de processamento, exposição a produtos químicos, métodos de cozimento, irradiação, congelamento e, principalmente, nutrição das aves (Froning et al., 1978).

Alguns carotenóides são precursores da síntese de vitamina A e podem também atuar como antioxidantes fisiológicos e nos mecanismos de resposta imune do animal (Prabhala e Scott, 1991). A capacidade de absorção dos carotenóides afeta a pigmentação dos tecidos (Ibarra, 1991). Pérez-Vendrell (2001), ao suplementar a ração para frangos de corte alimentados com dietas à base de milho e de sorgo com pigmentante xantofila, verificou que as aves que receberam milho apresentaram melhor pigmentação que aquelas que receberam sorgo. Pereira et al. (2001) avaliaram a deposição de pigmentos na carcaça de frangos de corte alimentados com dieta à base de sorgo e bixina (extrato de urucum) e observaram efeito pigmentante sobre a carcaça, à medida que se aumentou o nível de bixina. Porém, o nível máximo do pigmentante utilizado na pesquisa $(0,20 \%)$ não foi suficiente para alcançar a coloração desejável da carcaça das aves.

Este trabalho teve por objetivo avaliar o desempenho e a qualidade da carne de frangos de corte alimentados com diferentes níveis de sorgo em substituição ao milho.

\section{MATERIAL E MÉTODOS}

As aves foram distribuídas em um delineamento inteiramente ao acaso, com esquema fatorial $5 \times 2$ (cinco níveis de sorgo em substituição ao milho na ração - 0, 25, 50, 75 e 100\% - e dois sexos), com quatro repetições de 65 aves, totalizando 40 parcelas experimentais. Foram utilizados 2600 pintos de corte de um dia, de linhagem Ross 308, sexados e vacinados no incubatório contra a doença de Marek e, aos 10 dias de idade, contra a doença de Newcastle, via água de bebida. Foi adotado o sistema de manejo de criações comerciais.

O sorgo utilizado na fabricação das rações experimentais, cultivar SAARA, foi fornecido pela empresa Monsanto, localizada na cidade de Uberlândia-MG. O aminograma do sorgo e a 


\section{Garcia et al.}

composição bromatológica do sorgo e milho são apresentados na Tab. 1. As aves receberam ração (Tab. 2) e água à vontade durante todo o período de criação, que foi dividido em três fases: inicial
(1 a 21 dias), crescimento ( 22 a 35 dias) e final (36 a 42 dias). As rações foram formuladas de acordo com os níveis nutricionais normalmente utilizados em criações comerciais.

Tabela 1. Aminograma ${ }^{1}$ do sorgo e composição bromatológica do sorgo e do milho utilizado nas dietas experimentais de frangos de corte

\begin{tabular}{lccccc}
\hline Aminoácido (\%) & Total & Digestibilidade & Bromatologia & Sorgo $^{1}$ & Milho $^{2}$ \\
\hline Lisina & 0,18 & 0,14 & Umidade (\%) & 14,70 & 12,00 \\
Metionina & 0,14 & 0,12 & Proteína bruta (\%) & 7,87 & 8,51 \\
Metionina + Cistina & 0,28 & 0,17 & Cálcio (\%) & 0,03 & 0,02 \\
Treonina & 0,26 & 0,21 & Fósforo disponível (\%) & 0,09 & 0,09 \\
Triptofano & 0,15 & 0,10 & Fibra bruta (\%) & 2,03 & 1,78 \\
Valina & 0,37 & 0,30 & Extrato etéreo (\%) & 3,12 & 3,28 \\
Isoleucina & 0,33 & 0,28 & Taninos & 0,49 & - \\
Leucina & 1,00 & 0,96 & Energia metabolizável (kcal/kg) & 3252 & 3416 \\
Fenilalanina & 0,40 & 0,36 & - & - & - \\
Histidina & 0,16 & 0,10 & - & - & - \\
Arginina & 0,29 & 0,27 & - & - & - \\
\hline I'Valores analisados na Multimix-Nutrição Animal, Campinas-SP; ${ }^{2}$ valores analisados no Laboratório de Bromatologia da Faculdade
\end{tabular}

de Medicina Veterinária e Zootecnia - UNESP, Campus de Botucatu-SP.

$\mathrm{Na}$ análise estatística, usou-se o procedimento General Linear Models do SAS (User's..., 1988).

O ganho de peso das aves foi calculado ao final de cada fase, sendo todos os frangos pesados no $21^{\circ}, 35^{\circ}$ e $42^{\circ}$ dias de idade. O consumo de ração e a conversão alimentar foram calculados para cada fase.

Aos 42 dias de idade, cinco aves por repetição foram abatidas para avaliar o rendimento de carcaça inteira, do peito desossado, das pernas, das asas, do dorso e da gordura abdominal. Os valores percentuais do rendimento de carcaça foram calculados em relação ao peso vivo, enquanto o rendimento de cada parte foi calculado em relação ao peso da carcaça eviscerada.

Para as determinações de comprimento, largura e altura do peito, foi pesado o conjunto dos músculos peitorais, a fim de avaliar o peso total e a porcentagem de carne branca. Os músculos pectoralis major foram dissecados, pesados e, em seguida, mediu-se, com auxílio de um paquímetro, comprimento, largura e altura, considerando-se como valor final a média de dois filés para cada ave. A altura foi medida na parte mais espessa do músculo.
A determinação do $\mathrm{pH}$ foi realizada com um eletrodo de penetração, diretamente no peito e na coxa das aves, 24 horas post mortem. Essa medida foi feita em todas as aves amostradas para a determinação do rendimento da carcaça.

Para a determinação da perda de peso por cozimento e da força de cisalhamento, foi utilizado o músculo peitoral esquerdo da ave, o qual foi embalado em papel laminado e mantido em uma chapa elétrica de modelo comercial, com aquecimento nas duas faces, por aproximadamente oito minutos à temperatura de $85^{\circ} \mathrm{C}$. Depois de uma hora, a amostra de peito foi pesada. A diferença de peso entre peso do peito in natura e peso uma hora após o cozimento correspondeu à perda de peso por cozimento. As amostras, embaladas em papel absorvente e em sacos plásticos, foram armazenadas por 24 horas a $2^{\circ} \mathrm{C}$.

Para a determinação da força de cisalhamento (textura ou maciez), foram utilizadas as amostras usadas para a determinação da perda de peso por cozimento. Foram retiradas três amostras por filé, na forma de paralelepípedos com $2 \times 2 \times 1,13 \mathrm{~cm}$, as quais foram colocadas com as fibras orientadas no sentido perpendicular às lâminas do aparelho Warner-Bratzler, conforme a técnica descrita por Froning et al. (1978). 
Arq. Bras. Med. Vet. Zootec., v.57, n.5, p.634-643, 2005

Tabela 2. Composição percentual e calculada das dietas experimentais utilizadas na alimentação de frangos de corte

\begin{tabular}{|c|c|c|c|c|c|c|c|c|c|c|c|c|c|c|c|}
\hline \multirow{3}{*}{ Composição percentual } & \multicolumn{5}{|c|}{ Ração inicial } & \multirow{2}{*}{\multicolumn{5}{|c|}{$\begin{array}{c}\text { Ração de crescimento } \\
\text { Nível de substituicão (\%) }\end{array}$}} & \multicolumn{5}{|c|}{ Ração final } \\
\hline & \multicolumn{5}{|c|}{ Nível de substituição (\%) } & & & & & & \multicolumn{5}{|c|}{ Nível de substituição (\%) } \\
\hline & 0 & 25 & 50 & 75 & 100 & 0 & 25 & 50 & 75 & 100 & 0 & 25 & 50 & 75 & 100 \\
\hline Milho moído & 56,690 & 42,630 & 28,350 & 14,200 & 0,000 & 60,702 & 45,525 & 30,351 & 15,175 & 0,000 & 65,535 & 49,157 & 32,769 & 16,380 & 0,000 \\
\hline Farelo de soja & 36,286 & 35,700 & 35,498 & 35,093 & 34,748 & 30,986 & 30,986 & 30,975 & 30,929 & 30,882 & 26,912 & 27,309 & 27,309 & 27,051 & 26,480 \\
\hline Sorgo moído & 0,000 & 14,200 & 28,350 & 42,630 & 56,692 & 0,000 & 15,175 & 30,351 & 45,525 & 60,702 & 0,000 & 16,380 & 32,768 & 49,157 & 65,537 \\
\hline Óleo de soja & 2,977 & 3,410 & 3,700 & 3,950 & 4,400 & 4,000 & 4,310 & 4,618 & 4,928 & 5,236 & 4,285 & 4,654 & 4,988 & 5,322 & 5,848 \\
\hline Dl-metionina (99\%) & 0,231 & 0,231 & 0,231 & 0,231 & 0,231 & 0,150 & 0,154 & 0,159 & 0,163 & 0,168 & 0,162 & 0,174 & 0,154 & 0,139 & 0,148 \\
\hline L-lisina & 0,150 & 0,163 & 0,205 & 0,230 & 0,263 & 0,192 & 0,207 & 0,221 & 0,235 & 0,249 & 0,187 & 0,187 & 0,187 & 0,225 & 0,268 \\
\hline Fosfato bicálcico & 1,814 & 1,814 & 1,814 & 1,814 & 1,814 & 1,614 & 1,606 & 1,598 & 1,590 & 1,582 & 0,483 & 0,869 & 0,520 & 0,454 & 0,453 \\
\hline Calcário calcítico & 0,982 & 0,982 & 0,982 & 0,982 & 0,982 & 0,928 & 0,930 & 0,877 & 0,605 & 0,331 & 0,638 & 0,640 & 0,675 & 0,642 & 0,636 \\
\hline Suplemento vitamínico* & 0,400 & 0,400 & 0,400 & 0,400 & 0,400 & 0,400 & 0,400 & 0,400 & 0,400 & 0,400 & 0,200 & 0,200 & 0,200 & 0,200 & 0,200 \\
\hline Suplemento mineral* & 0,120 & 0,120 & 0,120 & 0,120 & 0,120 & 0,100 & 0,100 & 0,100 & 0,100 & 0,100 & 0,080 & 0,080 & 0,080 & 0,080 & 0,080 \\
\hline Inerte & 0,000 & 0,000 & 0,000 & 0,000 & 0,000 & 0,578 & 0,258 & 0,000 & 0,000 & 0,000 & 1,168 & 0,000 & 0,000 & 0,000 & 0,000 \\
\hline Sal & 0,350 & 0,350 & 0,350 & 0,350 & 0,350 & 0,350 & 0,350 & 0,350 & 0,350 & 0,350 & 0,350 & 0,350 & 0,350 & 0,350 & 0,350 \\
\hline Total & 100,00 & 100,00 & 100,00 & 100,00 & 100,00 & 100,00 & 100,00 & 100,00 & 100,00 & 100,00 & 100,00 & 100,00 & 100,00 & 100,00 & 100,00 \\
\hline \multicolumn{16}{|l|}{ Composição calculada } \\
\hline Energia metabolizável (kcal/kg) & 3000 & 3000 & 3000 & 3000 & 3000 & 3100 & 3100 & 3100 & 3100 & 3100 & 3200 & 3200 & 3200 & 3200 & 3200 \\
\hline Proteína bruta (\%) & 21,396 & 21,396 & 21,396 & 21,396 & 21,396 & 19,313 & 19,313 & 19,313 & 19,313 & 19,313 & 18,048 & 18,048 & 18,048 & 18,048 & 18,048 \\
\hline Cálcio (\%) & 0,960 & 0,960 & 0,960 & 0,960 & 0,960 & 0,874 & 0,874 & 0,874 & 0,874 & 0,874 & 0,800 & 0,800 & 0,800 & 0,800 & 0,800 \\
\hline Fósforo disponível (\%) & 0,450 & 0,450 & 0,450 & 0,450 & 0,450 & 0,406 & 0,406 & 0,406 & 0,406 & 0,406 & 0,365 & 0,365 & 0,365 & 0,365 & 0,365 \\
\hline Metionina (\%) & 0,492 & 0,492 & 0,492 & 0,492 & 0,492 & 0,453 & 0,453 & 0,453 & 0,453 & 0,453 & 0,410 & 0,410 & 0,410 & 0,410 & 0,410 \\
\hline $\mathrm{a}+$ cistina & 0,897 & 0,897 & 0,897 & 0,897 & 0,897 & 0,765 & 0,765 & 0,765 & 0,765 & 0,765 & 0,742 & 0,742 & 0,742 & 0,742 & 0,742 \\
\hline Lisina $(\%)$ & 1,263 & 1,263 & 1,263 & 1,263 & 1,263 & 1,156 & 1,156 & 1,156 & 1,156 & 1,156 & 1,040 & 1,040 & 1,040 & 1,040 & 1,040 \\
\hline Triptofano (\%) & 0,207 & 0,207 & 0,207 & 0,207 & 0,207 & 0,238 & 0,238 & 0,238 & 0,238 & 0,238 & 0,182 & 0,182 & 0,182 & 0,182 & 0,182 \\
\hline Treonina (\%) & 0,795 & 0,795 & 0,795 & 0,795 & 0,795 & 0,752 & 0,752 & 0,752 & 0,752 & 0,752 & 0,634 & 0,634 & 0,634 & 0,634 & 0,634 \\
\hline K (\%) & 0,501 & 0,501 & 0,501 & 0,501 & 0,501 & 0,752 & 0,752 & 0,752 & 0,752 & 0,752 & 0,454 & 0,454 & 0,454 & 0,454 & 0,454 \\
\hline $\mathrm{Na}(\%)$ & 0,222 & 0,222 & 0,222 & 0,222 & 0,222 & 0,178 & 0,178 & 0,178 & 0,178 & 0,178 & 0,192 & 0,192 & 0,192 & 0,192 & 0,192 \\
\hline $\mathrm{Cl}(\%)$ & 0,195 & 0,195 & 0,195 & 0,195 & 0,195 & 0,242 & 0,242 & 0,242 & 0,242 & 0,242 & 0,160 & 0,160 & 0,160 & 0,160 & 0,160 \\
\hline
\end{tabular}

Vitamina B12- 3125mg; Niacina A- 1.875.000 U, Vitamina D3- 625.000 UI, Vitamina E- 3.750mg; Vitamina K3- 300mg, Tiamina- 375mg; Riboflavina- 1.375mg; Piridoxina- 500mg;

Coccidiostático- 25.000mg; Antioxidante- 5.000mg. Suplemento Mineral: Ferro- 50.000mg; Cobre- 70.000mg; Manganês- 60.000; Zinco- 50.000mg; Iodo- 1.250mg; Selênio- 200mg. 
A avaliação da coloração da carne de peito e de coxas foi determinada no Laboratório de Análise Sensorial da Sadia, localizado em São Paulo-SP, com um espectrofotômetro Hunter, no sistema CIE. Foram avaliadas as características L (luminosidade - nível de escuro a claro), a (vermelho) e b (amarelo), com três repetições por ponto, em três diferentes regiões da superfície superior e inferior do músculo do peito e da superfície superior da coxa, de acordo com a metodologia proposta por Honikel (1998).

As análises sensoriais foram realizadas de acordo com a metodologia descrita por Roça (1988), utilizando as amostras de carne de peito de frangos machos alimentados com dietas contendo milho sem sorgo e ração contendo sorgo sem milho.

Foram feitas avaliações da composição química da carne do peito e da coxa e sobrecoxa in natura. Umidade, extrato etéreo e resíduo ruminal foram calculados segundo AOAC (Official... 1990). A proteína foi estimada pelo método de KjeldahlMicro (Official... 1990) para determinação do nitrogênio total e da proteína bruta.

\section{RESULTADOS E DISCUSSÕES}

Os resultados de ganho de peso, consumo de ração, conversão alimentar e mortalidade são apresentados nas Tab. 3, 4, 5 e 6, respectivamente. Não houve efeito significativo dos níveis de substituição do milho pelo sorgo em nenhuma das características de desempenho avaliadas. Resultados semelhantes foram encontrados por Fernandes et al. (2002) que, ao compararem o desempenho produtivo de frangos de corte alimentados com dietas à base de milho, milho:sorgo e sorgo, não observaram diferenças para as características de desempenho. Segundo esses autores, os resultados foram atribuídos à proximidade entre os valores nutricionais do milho e do sorgo e, também, porque é possível formular rações com valores nutricionais muito próximos, principalmente para energia metabolizável e proteína bruta para os dois cereais.

A avaliação da coloração da carne de peito e de coxas foi determinada no Laboratório de Análise Sensorial da Sadia, localizado em São Paulo-SP, com um espectrofotômetro Hunter, no sistema CIE. Foram avaliadas as características L (luminosidade - nível de escuro a claro), a (vermelho) e b (amarelo), com três repetições por ponto, em três diferentes regiões da superfície superior e inferior do músculo do peito e da superfície superior da coxa, de acordo com a metodologia proposta por Honikel (1998).

As análises sensoriais foram realizadas de acordo com a metodologia descrita por Roça (1988), utilizando as amostras de carne de peito de frangos machos alimentados com dietas contendo milho sem sorgo e ração contendo sorgo sem milho.

Foram feitas avaliações da composição química da carne do peito e da coxa e sobrecoxa in natura. Umidade, extrato etéreo e resíduo ruminal foram calculados segundo AOAC (Official... 1990). A proteína foi estimada pelo método de KjeldahlMicro (Official... 1990) para determinação do nitrogênio total e da proteína bruta.

Tabela 3. Ganho de peso (g) de frangos de corte alimentados com cinco níveis de sorgo em substituição ao milho

\begin{tabular}{|c|c|c|c|c|c|c|c|}
\hline \multirow{2}{*}{$\begin{array}{l}\text { Idade } \\
\text { (dias) }\end{array}$} & \multirow{2}{*}{ Sexo } & \multicolumn{6}{|c|}{ Nível de substituição do milho pelo sorgo (\%) } \\
\hline & & 0 & 25 & 50 & 75 & 100 & Média \\
\hline \multirow{3}{*}{$\begin{array}{l}1 \mathrm{a} 21 \\
\mathrm{CV}=1,6\end{array}$} & Macho & 807 & 809 & 816 & 812 & 812 & 811 \\
\hline & Fêmea & 811 & 814 & 818 & 814 & 800 & 811 \\
\hline & Média & 809 & 812 & 817 & 813 & 806 & - \\
\hline \multirow{3}{*}{$\begin{array}{l}22 \text { a } 35 \\
C V=11,4\end{array}$} & Macho & 1173 & 1130 & 1158 & 1181 & 1171 & 1163 \\
\hline & Fêmea & 1110 & 1230 & 1223 & 1167 & 1175 & 1181 \\
\hline & Média & 1141 & 1180 & 1191 & 1174 & 1173 & - \\
\hline \multirow{3}{*}{$\begin{array}{l}36 \text { a } 42 \\
C V=7,4\end{array}$} & Macho & 612 & 552 & 539 & 579 & 593 & 575 \\
\hline & Fêmea & 526 & 616 & 597 & 564 & 575 & 576 \\
\hline & Média & 569 & 584 & 568 & 571 & 584 & - \\
\hline \multirow{3}{*}{$\begin{array}{l}1 \mathrm{a} 42 \\
\mathrm{CV}=6,9\end{array}$} & Macho & 2592 & 2492 & 2514 & 2573 & 2576 & 2549 \\
\hline & Fêmea & 2448 & 2662 & 2639 & 2546 & 2551 & 2569 \\
\hline & Média & 2520 & 2577 & 2576 & 2559 & 2564 & - \\
\hline
\end{tabular}

$\mathrm{CV}=$ Coeficiente de variação $(\%)$. Diferenças entre níveis não foram significativas $(\mathrm{P}>0,05)$. 
Tabela 4. Consumo de ração $(\mathrm{g})$ de frangos de corte alimentados com cinco níveis de sorgo em substituição ao milho

\begin{tabular}{|c|c|c|c|c|c|c|c|}
\hline \multirow{2}{*}{$\begin{array}{l}\text { Idade } \\
\text { (dias) }\end{array}$} & \multirow{2}{*}{ Sexo } & \multicolumn{6}{|c|}{ Nível de substituição do milho pelo sorgo (\%) } \\
\hline & & 0 & 25 & 50 & 75 & 100 & Média \\
\hline \multirow{3}{*}{$\begin{array}{l}1 \text { a } 21 \\
C V=1,9\end{array}$} & Macho & 1150 & 1152 & 1156 & 1162 & 1157 & 1155 \\
\hline & Fêmea & 1142 & 1170 & 1151 & 1155 & 1161 & 1156 \\
\hline & Média & 1146 & 1161 & 1153 & 1159 & 1159 & - \\
\hline \multirow{3}{*}{$\begin{array}{l}22 \text { a } 35 \\
C V=6,9\end{array}$} & Macho & 2049 & 2013 & 2002 & 2072 & 2068 & 2041 \\
\hline & Fêmea & 2009 & 2123 & 2099 & 2062 & 2089 & 2077 \\
\hline & Média & 2029 & 2068 & 2051 & 2067 & 2079 & - \\
\hline \multirow{3}{*}{$\begin{array}{l}36 \text { a } 42 \\
C V=6,6\end{array}$} & Macho & 1129 & 1177 & 1161 & 1158 & 1179 & 1161 \\
\hline & Fêmea & 1173 & 1110 & 1232 & 1145 & 1147 & 1161 \\
\hline & Média & 1151 & 1144 & 1196 & 1152 & 1163 & - \\
\hline \multirow{3}{*}{$\begin{array}{l}1 \text { a } 42 \\
C V=4,8\end{array}$} & Macho & 4466 & 4401 & 4452 & 4491 & 4482 & 4458 \\
\hline & Fêmea & 4345 & 4584 & 4544 & 4437 & 4495 & 4481 \\
\hline & Média & 4406 & 4492 & 4498 & 4464 & 4488 & - \\
\hline
\end{tabular}

$\overline{\mathrm{CV}}=$ Coeficiente de variação (\%). Diferenças entre níveis não foram significativas $(\mathrm{P}>0,05)$.

Tabela 5. Conversão alimentar de frangos de corte alimentados com cinco níveis de sorgo em substituição ao milho

\begin{tabular}{|c|c|c|c|c|c|c|c|}
\hline \multirow{2}{*}{$\begin{array}{l}\text { Idade } \\
\text { (dias) }\end{array}$} & \multirow{2}{*}{ Sexo } & \multicolumn{6}{|c|}{ Nível de substituição do milho pelo sorgo (\%) } \\
\hline & & 0 & 25 & 50 & 75 & 100 & Média \\
\hline \multirow{3}{*}{$\begin{array}{l}1 \text { a } 21 \\
C V=1,7\end{array}$} & Macho & 1,42 & 1,42 & 1,42 & 1,43 & 1,42 & 1,42 \\
\hline & Fêmea & 1,41 & 1,43 & 1,41 & 1,42 & 1,45 & 1,42 \\
\hline & Média & 1,42 & 1,43 & 1,41 & 1,42 & 1,44 & - \\
\hline \multirow{3}{*}{$\begin{array}{l}22 \text { a } 35 \\
C V=4,6\end{array}$} & Macho & 1,79 & 1,81 & 1,81 & 1,78 & 1,79 & 1,79 \\
\hline & Fêmea & 1,81 & 1,76 & 1,76 & 1,79 & 1,79 & 1,78 \\
\hline & Média & 1,80 & 1,78 & 1,78 & 1,78 & 1,79 & - \\
\hline \multirow{3}{*}{$\begin{array}{l}36 \text { a } 42 \\
C V=3,2\end{array}$} & Macho & 2,07 & 2,22 & 2,30 & 2,18 & 2,14 & 2,18 \\
\hline & Fêmea & 2,28 & 2,13 & 2,14 & 2,18 & 2,19 & 2,18 \\
\hline & Média & 2,18 & 2,17 & 2,22 & 2,18 & 2,16 & - \\
\hline \multirow{3}{*}{$\begin{array}{l}1 \text { a } 42 \\
C V=2,1\end{array}$} & Macho & 1,74 & 1,77 & 1,78 & 1,75 & 1,75 & 1,76 \\
\hline & Fêmea & 1,77 & 1,74 & 1,73 & 1,75 & 1,77 & 1,75 \\
\hline & Média & 1,76 & 1,75 & 1,76 & 1,75 & 1,76 & - \\
\hline
\end{tabular}

$\overline{\mathrm{CV}}=$ Coeficiente de variação (\%). Diferenças entre níveis não foram significativas $(\mathrm{P}>0,05)$.

Tabela 6. Mortalidade (\%) de frangos de corte alimentados com cinco níveis de sorgo em substituição ao milho

\begin{tabular}{|c|c|c|c|c|c|c|c|}
\hline \multirow{2}{*}{$\begin{array}{l}\text { Idade } \\
\text { (dias) }\end{array}$} & \multirow{2}{*}{ Sexo } & \multicolumn{6}{|c|}{ Nível de substituição do milho pelo sorgo (\%) } \\
\hline & & 0 & 25 & 50 & 75 & 100 & Média \\
\hline \multirow{3}{*}{$\begin{array}{l}1 \text { a } 21 \\
46,9\end{array}$} & Macho & 0,71 & 0,90 & 1,02 & 1,09 & 1,02 & 0,94 \\
\hline & Fêmea & 0,90 & 0,90 & 1,28 & 1,02 & 0,90 & 1,00 \\
\hline & Média & 0,80 & 0,90 & 1,15 & 1,05 & 0,96 & - \\
\hline \multirow{3}{*}{$\begin{array}{l}22 \text { a } 35 \\
43,3\end{array}$} & Macho & 1,21 & 1,09 & 1,63 & 0,90 & 1,09 & 1,18 \\
\hline & Fêmea & 0,71 & 1,21 & 1,28 & 0,90 & 0,90 & 1,00 \\
\hline & Média & 0,96 & 1,15 & 1,45 & 0,90 & 0,99 & - \\
\hline \multirow{3}{*}{$\begin{array}{l}36 \text { a } 42 \\
49,1\end{array}$} & Macho & 1,44 & 1,02 & 1,23 & 1,34 & 1,22 & 1,25 \\
\hline & Fêmea & 0,90 & 1,82 & 1,02 & 1,22 & 1,40 & 1,27 \\
\hline & Média & 1,17 & 1,42 & 1,13 & 1,28 & 1,31 & - \\
\hline \multirow{3}{*}{$\begin{array}{l}1 \text { a } 42 \\
47,9\end{array}$} & Macho & 1,77 & 1,50 & 2,00 & 1,72 & 1,61 & 1,72 \\
\hline & Fêmea & 1,09 & 2,25 & 1,93 & 1,46 & 1,62 & 1,67 \\
\hline & Média & 1,43 & 1,87 & 1,97 & 1,59 & 1,61 & - \\
\hline
\end{tabular}

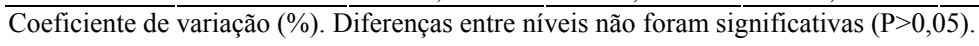


Os resultados de peso vivo, peso da carcaça, rendimento de carcaça e das carnes de peito e pernas são apresentados nas Tab. 7 e 8 . Houve efeito $(\mathrm{P}<0,05)$ apenas de sexo para o peso vivo, peso da carcaça, rendimento de pernas, porcentagem de gordura abdominal e rendimento de carne de pernas. Os machos apresentaram os maiores valores, com exceção da porcentagem de gordura abdominal e conversão de ração em carne de peito e pernas que foi maior para as fêmeas. Resultados semelhantes foram encontrados por Gualtieri et al. (1990) que, ao avaliarem três níveis de substituição do milho pelo sorgo $(0,50$ e $100 \%)$ em dietas de frangos de corte, não encontraram diferenças significativas para o peso vivo, peso e rendimento da carcaça e rendimento dos cortes, o que, segundo os autores, deve-se à proximidade dos valores nutricionais entre milho e sorgo.

Os resultados encontrados para o $\mathrm{pH}$ da carne de peito e pernas 24 horas post mortem são apresentados na Tab. 9. Os machos apresentaram maiores valores de $\mathrm{pH}(\mathrm{P}<0,05)$ do que as fêmeas. Para os níveis de substituição do milho pelo sorgo, ocorreu diminuição dos valores de pH à medida que aumentaram os níveis de substituição. Jones e Grey (1989) descreveram variações médias de $\mathrm{pH}$ entre 5,6 a 5,8, e Sams e Mills (1993) relataram resultados entre 5,7 e 5,8.

Tabela 7. Peso vivo $(\mathrm{g})$ e peso da carcaça $(\mathrm{g})$ de frangos de corte alimentados com cinco níveis de sorgo em substituição ao milho

\begin{tabular}{lccccccc}
\hline \multirow{2}{*}{ Característica } & \multirow{2}{*}{ Sexo } & \multicolumn{7}{c}{ Nível de substituição do milho pelo sorgo (\%) } \\
\cline { 3 - 7 } & & 0 & 25 & 50 & 75 & 100 & Média \\
\hline \multirow{2}{*}{ Peso vivo } & Macho & 2778 & 2885 & 2708 & 2866 & 2804 & $2808 \mathrm{~A}$ \\
$\mathrm{CV}=2,8$ & Fêmea & 2409 & 2475 & 2425 & 2440 & 2438 & $2437 \mathrm{~B}$ \\
& Média & $2594 \mathrm{ab}$ & $2680 \mathrm{a}$ & $2567 \mathrm{ab}$ & $2653 \mathrm{~b}$ & $2621 \mathrm{ab}$ & - \\
\multirow{2}{*}{ Peso da carcaça } & Macho & 1967 & 2051 & 1913 & 2012 & 1977 & $1984 \mathrm{~A}$ \\
$\mathrm{CV}=3,8$ & Fêmea & 1731 & 1760 & 1697 & 1733 & 1734 & $1731 \mathrm{~B}$
\end{tabular}

Médias seguidas de letras distintas minúsculas na linha e letras distintas maiúsculas na coluna diferem entre si pelo teste Tukey $(\mathrm{P}<0,05) ; \mathrm{CV}=$ coeficiente de variação $(\%)$.

Tabela 8. Rendimentos (\%) da carcaça e das partes da carcaça de frangos de corte alimentados com cinco níveis de sorgo em substituição ao milho

\begin{tabular}{lccccccc}
\hline \multirow{2}{*}{ Característica } & \multirow{2}{*}{ Sexo } & \multicolumn{7}{c}{ Nível de substituição do milho pelo sorgo (\%) } \\
\cline { 3 - 8 } Carcaça & Macho & 70,82 & 25 & 50 & 75 & 100 & Média \\
CV=1,6 & Fêmea & 71,84 & 71,09 & 70,65 & 70,19 & 70,44 & 70,64 \\
& Média & 71,33 & 71,09 & 70,97 & 71,04 & 71,13 & 71,02 \\
Perna & Macho & 32,05 & 31,59 & 32,71 & 31,35 & 31,48 & $31,84 \mathrm{~A}$ \\
CV=2,8 & Fêmea & 30,61 & 31,31 & 30,68 & 30,87 & 30,18 & $30,73 \mathrm{~B}$ \\
& Média & 31,33 & 31,45 & 31,70 & 31,11 & 30,83 & - \\
Asas & Macho & 11,61 & 11,58 & 11,66 & 11,51 & 11,69 & 11,61 \\
CV=3,8 & Fêmea & 11,21 & 11,50 & 11,69 & 11,53 & 11,45 & 11,48 \\
& Média & 11,41 & 11,54 & 11,67 & 11,52 & 11,57 & - \\
Peito & Macho & 35,88 & 36,71 & 35,87 & 36,57 & 36,97 & 36,40 \\
CV=3,1 & Fêmea & 36,93 & 37,76 & 37,50 & 35,92 & 36,50 & 36,92 \\
\multirow{2}{*}{ Dorso } & Média & 36,40 & 37,24 & 36,68 & 36,25 & 36,73 & - \\
CV=4,8 & Macho & 20,51 & 20,70 & 21,06 & 21,27 & 21,67 & 21,04 \\
& Fêmea & 19,78 & 21,03 & 20,35 & 21,67 & 20,59 & 20,68 \\
Gordura & Média & 20,14 & 20,87 & 20,71 & 21,47 & 21,13 & - \\
CV=8,8 & Macho & 3,16 & 2,47 & 2,76 & 2,78 & 3,04 & $2,84 \mathrm{~B}$ \\
\hline
\end{tabular}

Médias seguidas de letras distintas minúsculas na linha e letras distintas maiúsculas na coluna diferem entre si pelo teste Tukey $(\mathrm{P}<0,05) ; \mathrm{CV}=$ coeficiente de variação $(\%)$. 
Tabela 9. Valores de $\mathrm{pH}$, medidas físicas $(\mathrm{cm})$, perda de peso por cozimento (PPC) (g) e força de cisalhamento $(\mathrm{FC})\left(\mathrm{kgf} / \mathrm{cm}^{2}\right)$ da carne de peito e de pernas de frangos de corte alimentados com cinco níveis de sorgo em substituição ao milho

\begin{tabular}{|c|c|c|c|c|c|c|c|}
\hline \multirow{2}{*}{ Característica } & \multirow{2}{*}{ Sexo } & \multicolumn{6}{|c|}{ Nível de substituição do milho pelo sorgo (\%) } \\
\hline & & 0 & 25 & 50 & 75 & 100 & Média \\
\hline $\mathrm{pH}$ & Macho & 6,04 & 6,09 & 6,09 & 6,00 & 5,90 & $6,02 \mathrm{~A}$ \\
\hline Peito & Fêmea & 5,97 & 5,98 & 5,96 & 5,84 & 5,89 & $5,93 \mathrm{~B}$ \\
\hline $\mathrm{CV}=1,1$ & Média & $6,00 \mathrm{a}$ & 6,03 a & $6,02 \mathrm{a}$ & $5,92 \mathrm{ab}$ & $5,89 \mathrm{~b}$ & - \\
\hline $\mathrm{pH}$ & Macho & 6,11 & 6,13 & 6,12 & 6,02 & 6,00 & $6,08 \mathrm{~A}$ \\
\hline Pernas & Fêmea & 6,10 & 6,09 & 6,05 & 5,93 & 5,98 & $6,03 \mathrm{~B}$ \\
\hline $\mathrm{CV}=0,9$ & Média & $6,10 \mathrm{a}$ & $6,11 \mathrm{a}$ & $6,09 \mathrm{a}$ & $5,98 \mathrm{~b}$ & $5,99 \mathrm{~b}$ & - \\
\hline \multirow{3}{*}{$\begin{array}{l}\text { Comprimento } \\
\mathrm{CV}=2,2\end{array}$} & Macho & 16,41 & 16,62 & 15,87 & 15,79 & 16,00 & $16,14 \mathrm{~A}$ \\
\hline & Fêmea & 15,66 & 15,66 & 15,46 & 14,50 & 14,79 & $15,21 \mathrm{~B}$ \\
\hline & Média & $16,04 \mathrm{a}$ & $16,14 \mathrm{a}$ & $15,66 \mathrm{ab}$ & $15,14 b$ & $15,39 \mathrm{~b}$ & - \\
\hline \multirow{3}{*}{$\begin{array}{l}\text { Largura } \\
\mathrm{CV}=4,4\end{array}$} & Macho & 7,70 & 7,46 & 7,41 & 7,79 & 7,99 & 7,67 A \\
\hline & Fêmea & 7,12 & 7,25 & 7,45 & 7,20 & 7,33 & $7,27 \mathrm{~B}$ \\
\hline & Média & 7,41 & 7,35 & 7,43 & 7,49 & 7,66 & - \\
\hline \multirow{3}{*}{$\begin{array}{c}\text { Espessura } \\
C V=6,7\end{array}$} & Macho & 2,17 & 2,48 & 2,34 & 2,53 & 2,33 & $2,37 \mathrm{~A}$ \\
\hline & Fêmea & 2,13 & 2,24 & 2,07 & 2,28 & 2,18 & $2,18 \mathrm{~B}$ \\
\hline & Média & 2,15 & 2,36 & 2,20 & 2,40 & 2,25 & - \\
\hline \multirow{3}{*}{$\begin{array}{c}\text { PPC } \\
\mathrm{CV}=11,4\end{array}$} & Macho & 41,96 & 36,67 & 37,60 & 41,28 & 40,50 & $39,60 \mathrm{~A}$ \\
\hline & Fêmea & 32,40 & 35,35 & 36,29 & 37,39 & 40,41 & $36,37 \mathrm{~B}$ \\
\hline & Média & 37,18 & 36,01 & 36,94 & 39,33 & 40,46 & - \\
\hline \multirow{3}{*}{$\begin{array}{c}\mathrm{FC} \\
\mathrm{CV}=15,6\end{array}$} & Macho & 3,44 & 3,23 & 4,19 & 4,78 & 4,77 & $4,08 \mathrm{~A}$ \\
\hline & Fêmea & 3,10 & 3,05 & 3,43 & 2,76 & 3,39 & $3,14 \mathrm{~B}$ \\
\hline & Média & $3,27 \mathrm{ab}$ & $3,14 \mathrm{~b}$ & $3,81 \mathrm{ab}$ & $3,77 \mathrm{ab}$ & $4,08 \mathrm{a}$ & - \\
\hline
\end{tabular}

Médias seguidas de letras distintas minúsculas na linha e letras distintas maiúsculas na coluna diferem entre si pelo teste Tukey $(\mathrm{P}<0,05) ; \mathrm{CV}=$ coeficiente de variação $(\%)$.

Os valores encontrados para as medidas físicas da carne de peito são apresentados na Tab. 9. Todas as medidas apresentaram efeito de sexo, sendo que os machos apresentaram sempre os maiores valores, semelhante aos resultados de Robinson et al., (1996) e Lubritz (1997), os quais afirmaram que as medidas físicas da carne de peito de frangos de corte podem ser afetadas por diversos fatores, dentre eles linhagem, idade e, principalmente, sexo. Houve apenas diminuição $(\mathrm{P}<0,05)$ no comprimento do filé à medida que foram aumentados os níveis de substituição do milho pelo sorgo.

Os valores observados para a perda de peso por cozimento e a força de cisalhamento $\left(\mathrm{kgf} / \mathrm{cm}^{2}\right)$ são apresentados na Tab. 9. Ocorreu maior $(\mathrm{P}<0,05)$ perda de peso por cozimento na carne de peito dos machos e também maior força de cisalhamento, o que está de acordo com Bressan (1998). A substituição do milho pelo sorgo apresentou efeito $(\mathrm{P}<0,05)$ apenas para a força de cisalhamento, porém o valor encontrado para o nível zero de substituição não diferiu do valor encontrado para o maior nível.
Para a coloração da carne do peito e pernas, os valores $\mathbf{L}$, a e b são apresentados na Tab. 10. Observou-se aumento no valor $\mathbf{L}$ e diminuição de $\mathbf{a}$ e $\mathbf{b}(\mathrm{P}<0,05)$ em ambos os lados do peito à medida que aumentaram os níveis de substituição, semelhante aos resultados de Froning (1978). Esse autor afirmou que a pigmentação da carcaça de frangos de corte depende de diversos fatores, dentre eles a nutrição. Contudo, na carne das pernas, apenas houve diminuição de a à medida que aumentaram os níveis de substituição. Pereira et al. (2001) avaliaram a deposição de pigmentos na carcaça de frangos de corte alimentados com dieta à base de sorgo e bixina (extrato de urucum) e observaram que houve efeito pigmentante sobre a carcaça à medida que se aumentou o nível de bixina, porém o nível máximo do pigmentante utilizado na pesquisa $(0,20 \%)$ não foi suficiente para alcançar a coloração desejável da carcaça das aves.

Quanto à composição química da carne do peito e das pernas (Tab. 11), não houve efeito da substituição do milho pelo sorgo $(\mathrm{P}>0,05)$, semelhante aos resultados obtidos por Honikel (1998). 


\section{Garcia et al.}

Tabela 10. Valores L, a e b da carne de peito e pernas avaliados em duas regiões (superior e inferior) de frangos de corte alimentados com cinco níveis de sorgo em substituição ao milho

\begin{tabular}{lcccccc}
\hline & & \multicolumn{5}{c}{ Nível de substituição do milho pelo sorgo (\%) } \\
\cline { 3 - 7 } Característica & $\mathrm{CV}$ & 0 & 25 & 50 & 75 & 100 \\
\cline { 3 - 7 } & & \multicolumn{5}{c}{ Carne de peito } \\
\hline Valor L (sup.) & 4,05 & 49,99 & 51,48 & 51,35 & 50,96 & 52,01 \\
Valor a (sup.) & 19,48 & $1,28 \mathrm{a}$ & $-0,01 \mathrm{~b}$ & $-0,23 \mathrm{~b}$ & $-0,64 \mathrm{~b}$ & $-0,95 \mathrm{~b}$ \\
Valor b (sup.) & 13,68 & $7,98 \mathrm{a}$ & $6,12 \mathrm{ab}$ & $5,78 \mathrm{ab}$ & $5,44 \mathrm{ab}$ & $4,24 \mathrm{~b}$ \\
Valor L (inf.) & 5,59 & 49,40 & 49,43 & 49,88 & 50,12 & 50,86 \\
Valor a (inf.) & 13,04 & $1,26 \mathrm{a}$ & $-0,17 \mathrm{ab}$ & $-0,74 \mathrm{~b}$ & $-1,89 \mathrm{~b}$ & $-2,09 \mathrm{~b}$ \\
Valor b (inf.) & 10,46 & $14,50 \mathrm{a}$ & $11,78 \mathrm{~b}$ & $10,72 \mathrm{~b}$ & $8,94 \mathrm{c}$ & $7,99 \mathrm{c}$ \\
\hline & & \multicolumn{5}{c}{ Carne de pernas } \\
\hline Valor L (sup.) & 6,61 & 50,85 & 51,97 & 51,96 & 52,29 & 53,25 \\
Valor a (sup.) & 59,77 & $4,34 \mathrm{a}$ & $3,67 \mathrm{ab}$ & $3,37 \mathrm{~b}$ & $1,68 \mathrm{ab}$ & $1,59 \mathrm{~b}$ \\
Valor b (sup.) & 15,83 & 11,69 & 11,24 & 10,57 & 8,68 & 7,59 \\
Valor L (inf.) & 6,59 & 50,43 & 51,12 & 51,52 & 51,98 & 52,95 \\
Valor a (inf.) & 12,04 & 4,22 & 3,57 & 3,13 & 1,54 & 1,47 \\
Valor b (inf.) & 11,46 & 11,21 & 11,03 & 10,04 & 8,76 & 7,15 \\
\hline
\end{tabular}

Médias seguidas de letras distintas minúsculas na linha e letras distintas maiúsculas na coluna diferem entre si pelo teste Tukey $(\mathrm{P}<0,05)$; $\mathrm{CV}=$ coeficiente de variação $(\%)$. Valor $\mathrm{L}=$ luminosidade; valor $\mathrm{a}=$ vermelho; valor $\mathrm{b}=$ amarelo. Sup.= superior; inf.= inferior.

Tabela 11. Composição química (\%) da carne do peito e das pernas de frangos de corte, machos, segundo o nível de substituição do milho pelo sorgo

\begin{tabular}{llcccc}
\hline \multirow{2}{*}{ Composição } & & \multirow{2}{*}{ CV } & \multicolumn{3}{c}{ Nível de substituição do milho pelo sorgo (\%) } \\
\cline { 4 - 6 } Matéria seca & Peito & 2,0 & 28,12 & 50 & 100 \\
& Coxa & 2,3 & 28,14 & 27,68 & 27,88 \\
\multirow{2}{*}{ Umidade } & Peito & 0,8 & 71,88 & 28,71 & 28,21 \\
& Coxa & 0,9 & 71,86 & 72,32 & 72,12 \\
\multirow{2}{*}{ Proteína bruta } & Peito & 2,6 & 23,83 & 71,29 & 71,79 \\
& Coxa & 4,0 & 19,35 & 23,57 & 23,72 \\
\multirow{2}{*}{ Extrato etéreo } & Peito & 8,9 & 1,16 & 20,22 & 19,63 \\
& Coxa & 12,1 & 5,53 & 1,17 & 1,23 \\
\multirow{2}{*}{ Cinza } & Peito & 10,0 & 1,20 & 5,91 & 5,29 \\
& Coxa & 7,4 & 1,01 & 1,16 & 1,14 \\
\hline
\end{tabular}

$\overline{\mathrm{CV}}=$ coeficiente de variação.

Os níveis de substituição do milho pelo sorgo não influenciaram $(\mathrm{P}>0,05)$ as características sensoriais da carne de peito (Tab. 12), exceto para mastigabilidade. As aves alimentadas com dieta à base de milho apresentaram maior grau de insatisfação na escala estruturada, o que, segundo Roça et al.(1988), pode ser atribuído a diferenças entre provadores, pois os valores observados são muito próximos.

\section{CONCLUSÕES}

O sorgo pode ser recomendado para substituição do milho em dietas de frangos de corte, pois não promove alterações no desempenho e na qualidade da carne. Na substituição, pode ocorrer diminuição da coloração da carne, o que pode ser resolvido com o uso de pigmentantes naturais ou sintéticos adicionados às dietas. 
Tabela 12. Análise sensorial da carne de peito de frangos de corte segundo o nível de substituição do milho pelo sorgo

\begin{tabular}{lcc}
\hline Característica & Milho (100\%) & Sorgo (100\%) \\
\hline Intensidade de aroma & 7,11 & 7,18 \\
Aroma estranho $^{2}$ & 1,00 & 1,29 \\
Sabor $^{3}$ & 7,36 & 7,49 \\
Sabor estranho $^{4}$ & 1,14 & 1,00 \\
Maciez $^{5}$ & 3,0 & 3,86 \\
Suculência $^{6}$ & 5,43 & 5,14 \\
Mastigabilidade $^{7}$ & $6,61 \mathrm{a}$ & $5,70 \mathrm{~b}$ \\
Cor $^{8}$ & 7,76 & 7,44 \\
Aparência geral $^{9}$ & 7,71 & 7,71 \\
\hline
\end{tabular}

${ }^{1}$ Escala variando do sem aroma ao aroma muito intenso e característico; ${ }^{2}$ 1-nenhum, 2-extremamente fraco, 3-muito fraco, 4-fraco, 5-moderadamente fraco, 6-moderadamente forte, 7 -forte, 8 -muito forte, 9 -extremamente forte; ${ }^{3}$ escala variando do muito ruim ao muito bom.; ${ }^{4} 1$-nenhum, 2extremamente fraco, 3-muito fraco, 4-fraco, 5moderadamente fraco, 6-moderadamente forte, 7-forte, 8muito forte, 9-extremamente forte; ${ }^{5} 1$-extremamente macia (catupiri), 2-muito macia, 3-moderadamente macia, 4-macia, 5-nem macia nem dura (azeitona), 6-levemente dura, 7moderadamente dura, 8-muito dura, extremamente dura (bala soft); ${ }^{6}$ 1-extremamente seca, 2-muito seca, 3-moderadamente seca, 4-levemente seca, 5-nem seca nem suculenta, 6levemente suculenta, 7-moderadamente suculenta, 8-muito suculenta, 9-extremamente suculenta; ${ }^{7}$ escala variando de elástica, borrachenta e de difícil deglutição a facilmente desintegrável na boca e de fácil deglutição; ${ }^{8}$ escala variando de não característica a característica; ${ }^{9}$ escala variando de péssima a muito boa.

\section{REFERÊNCIAS BIBLIOGRÁFICAS}

BRESSAN, C. Efeito dos fatores pré-abate sobre a qualidade do peito de frango. 1998. 179f. Tese (Doutorado) - Faculdade de Engenharia de Alimentos, Unicamp, Campinas, SP.

FERNANDES, E.A.; MARCACINE, B.A.; TESINI, J.R.M. et al. Substituição do milho por sorgo com e sem adição de enzimas em rações para frangos de corte. In: CONFERÊNCIA APINCO DE CIÊNCIA E TECNOLOGIA AVÍCOLAS, 2002, Campinas, SP. Anais... Campinas:FACTA, 2002. p.34.

FRONING, G.W.; BABJI, A.S.; MATHER, F.B. The effect of preslaughter temperatures, stress, struggle and anesthetiztion on color and textural characteristics of turkey muscle. Poult. Sci., v.57, p.630-633, 1978.

GUALTIERI, M.; RAPACCINI, S. Sorghum grain in poultry feeding. World's Poult. Sci. J., v.46, p.246-254, 1990.

HONIKEL, K.O. Reference methods for the assessment of physical characteristics of meat. Meat Sci., v.49, p.447457, 1998.
IBARRA， B.M.; NEUCERE， N.J.; SUMRELL， G. Evaluation of two pigmentation programs in broilers. Poult. Sci., v.70, suppl. 1, p.57, 1991. (Abstract).

IBRAHIM, S.; MOHAMMED, K.S.; SOLIMAN, H. et al. Recommended levels of available phosphorus for broilers fed starting diets containing Sudanese sorghum. Nutr. Abstr. Rev., v.61, p.61, 1991.

JONES, J.M.; GREY, T.C. Influence of processing on product quality and yield. In: MEAD, G.C. (Ed.). Processing of poultry. London, 1989. p.127-130.

LUBRITZ, S.L. A statistical model for white meat yield in broiler. J. Appl. Poult. Res., v.6, p.253-259, 1997.

MUSHARAF, N.A.; LATSHAW, J.D. Effect of tannin extraction on the feeding value of grain sorghum in broiler starter diets. Sudan J. Anim. Prod., v.4, p.53-64, 1991.

NUTRIENT requeriments of poultry. 9.ed. Washington: Natl. Acad. Press, 1994. 156p.

OFFICIAL methods of analysis. 15.ed. Washington: AOAC, 1990. 1298p.

PEREIRA, A.V.; ARIKI, J.; KISHIBE, R. et al. Deposição de pigmentos em frangos de corte alimentados com ração à base de sorgo e bixina. In: CONFERÊNCIA APINCO DE CIÊNCIA E TECNOLOGIA AVÍCOLA, 2001, Campinas. Anais... Campinas:FACTA, 2001. p.33.

PÉREZ-VENDRELL, A.M. Influence of source and ratio of xanthophyll pigments on broiler chicken pigmentation and performance. Poult Sci., v.80, p.320-326, 2001.

PRABHALA, R.H.; SCOTT, M.L. The effect of 13-cis retinoic acid and beta-carotene on cellular immunity in humans. Cancer, v.67, p.1556-1560, 1991.

ROBINSON, F.E.; ROBINSON, N.A.; TURNER, B.V. et al. Breast muscle area, weight and thickness in four strain crosses of commercial broilers. In: POULTRY SCIENCE ANNUAL MEETING, 85., 1996, Louisville. Proceedings... Louisville: PSA, 1996. p.57.

ROÇA, R.O.; SERRANO, A.M.; BONASSI, I.A. Utilização de toucinho na elaboração de fiambres com carne de frango. Ciênc. Tecnol. Alim., v.8, p.67-76, 1988.

ROSTAGNO, H.S. Energia metabolizável do milho e do sorgo com diferentes conteúdos de tanino para aves. Rev. Bras. Zootec., v.6, p.304-318, 1977.

SAMS, A.R.; MILLS, K.A. The effect of feed withdrawal duration on the responsiveness of broiler pectoralis to rigor mortis acceleration. Poult. Sci., v.72, p.1789-1796. 1993.

TREVINO, J.; ZEFFERIES, D.; HOUSTON, B. Effects of tannin from faba beans (Vicia faba) on the digeston of starch by growing chicks. Anim. Feed Sci. Technol., v.37, p.345-349, 1992.

USER'S guide: statistics. Cary, NC: SAS Institute, 1988. 